\title{
Potential return on investment for implementation of perioperative goal-directed fluid therapy in major surgery: a nationwide database study
}

Frederic Michard ${ }^{1 *}$, William K. Mountford ${ }^{2,3}$, Michelle R. Krukas ${ }^{2,4}$, Frank R. Ernst ${ }^{2,5}$ and Sandy L. Fogel ${ }^{6}$

\begin{abstract}
Background: Preventable postsurgical complications are increasingly recognized as a major clinical and economic burden. A recent meta-analysis showed a 17-29\% decrease in postoperative morbidity with goal-directed fluid therapy. Our objective was to estimate the potential economic impact of perioperative goal-directed fluid therapy.

Methods: We studied 204,680 adult patients from 541 US hospitals who had a major non-cardiac surgical procedure between January 2011 and June 2013. Hospital costs (including 30-day readmission costs) in patients with and without complications were extracted from the Premier Inc. research database, and potential cost-savings associated with a $17-29 \%$ decrease in postoperative morbidity were estimated.

Results: A total of 76,807 patients developed one or more postsurgical complications (morbidity rate $37.5 \%$ ). In patients with and without complications, hospital costs were US\$27,607 $\pm 32,788$ and US\$15,783 $\pm 12,282(p<0.0001)$, respectively. Morbidity rate was anticipated to decrease to $26.6-31.1 \%$ with goal-directed fluid therapy, yielding potential gross cost-savings of US\$153-263 million for the study period, US\$61-105 million per year, or US\$754-1286 per patient. Potential savings per patient were highly variable from one surgical procedure to the other, ranging from US\$354-604 for femur and hip-fracture repair to US\$3515-5996 for esophagectomies. When taking into account the volume of procedures, the total potential savings per year were the most significant (US\$32-55 million) for colectomies.

Conclusions: Postsurgical complications occurred in more than one third of our study population and had a dramatic impact on hospital costs. With goal-directed fluid therapy, potential cost-savings per patient were US\$754-1286. The highest cost-savings per year were observed for colectomies. These projections should help hospitals estimate the return on investment when considering the implementation of goal-directed fluid therapy.
\end{abstract}

Keywords: Surgery, Complications, Costs, Goal-directed fluid therapy, Savings, Return on investment

\section{Background}

Preventable postoperative complications are increasingly recognized as a major healthcare burden (Birkmeyer et al. 2012; Dimick et al. 2006). After major operations, especially in patients with co-morbidities, complications are not exceptions (Ghaferi et al. 2009) and have adverse effects on long-term quality of life and survival (Khuri et al. 2005; Brown et al. 2014; Artinyan et al. 2015). They are

\footnotetext{
* Correspondence: frederic.michard@bluewin.ch

${ }^{1}$ Department of Critical Care, Edwards Lifesciences, 1 Edwards Way, Irvine,

CA, USA

Full list of author information is available at the end of the article
}

also responsible for a significant increase in hospital length of stay (LOS) (Eappen et al. 2013), readmission rates (Lawson et al. 2013; Merkow et al. 2015), and costs (Eappen et al. 2013; Dimick et al. 2004; Wick et al. 2011).

Perioperative fluid management is a key determinant of postoperative outcome. Both hypovolemia and fluid overload are associated with an increase in complications after surgery (Bellamy 2006). For a given surgical procedure, studies have shown a large intra- and interpractitioner variability in the amount of fluid administered during the perioperative period (Lilot et al. 2015). Goal-directed fluid therapy (GDFT) consists of assessing 
individual fluid needs during and/or after surgery by monitoring flow parameters such as stroke volume and cardiac output (Pearse et al. 2014). A recent meta-analysis of 38 randomized controlled trials showed that the use of GDFT decreases the rate of patients developing one or more complications by 17-29 \% (Pearse et al. 2014). Fuelled by this body of evidence, consensus statements (Mythen et al. 2012; Navarro et al. 2015) and guidelines (Vallet et al. 2013; Gustafsson et al. 2013) have been published, and GDFT has been integrated into the Enhanced Recovery in NSQIP (ERIN) collaborative. But today, the adoption of GDFT is still very limited in the USA (Cannesson et al. 2011; Miller et al. 2011). One of the barriers to the hospital adoption of GDFT may be the short-term financial investment necessary to acquire cardiac output-monitoring technologies. To ensure a fair economic evaluation, this investment must be balanced with the economic benefits related to the decrease in complications that is expected from the implementation of GDFT.

The goals of our study were twofold: describe the economic consequences of postoperative complications in a nationwide population of patients undergoing major non-cardiac surgery and estimate the economic impact of the reduction in postoperative morbidity expected from GDFT. This estimation should help hospitals to estimate the return on investment when considering the implementation of GDFT.

\section{Methods}

\section{Data source}

De-identified data from all adult inpatients, who had major non-cardiac surgery between January 2011 and June 2013, were selected from the Premier research database. The Premier research database contains patient data from over 600 US hospitals spanning all geographic regions, containing teaching and non-teaching as well as urban and rural hospitals of all sizes. Examination of the database allows the determination of patients' characteristics, postsurgical complications, and costs of care. The database complies with the Health Insurance Portability and Accountability Act of 1996 (HIPAA) and other related regulations. Any institutional review board approval was not sought because of the pre-existing, retrospective, and de-identified nature of the data.

\section{Patient selection}

Ten major surgical procedures were selected based on previous studies showing positive outcomes associated with the use of GDFT (Benes et al. 2010; Bisgaard et al. 2013; Boyd et al. 1993; Gan et al. 2002; Kuper et al. 2011; Lobo et al. 2000; Noblett et al. 2006; Pearse et al. 2005; Pillai et al. 2011; Ramsingh et al. 2013; Sinclair et al. 1997; Ueno et al. 1998; Venn et al. 2002; Wakeling et al. 2005; Wilson et al. 1999). Corresponding International
Classification of Diseases, Ninth Revision, Clinical Modification (ICD-9) codes were used to search specific procedures in the Premier research database (see Additional file 1: Table S1). Because GDFT has thus far been shown to be effective only in adults, those under 18 years of age were excluded. Patients in whom cardiac output was monitored on the day of surgery were also excluded, since they may have received GDFT.

\section{Patient characteristic data collection}

Patients' characteristics, including gender, age, and co-morbidities (based on ICD-9 diagnosis codes) were tabulated. The Charlson Co-morbidity Index (CCI) was calculated as previously described (Charlson et al. 1994). Twenty six infectious, gastro-intestinal, respiratory, renal, cardiovascular, neurologic, and hematologic inhospital postoperative complications were identified using ICD-9 diagnosis codes, ensuring that the diagnosis was not determined to be present at admission (see Additional file 2: Table S2). Morbidity rate was defined as the proportion of patients developing one or more complications during the index hospital stay. Patients were sorted into two groups: those with one or more complications and those without any complications. For each group, hospital length of stay and readmission rates at 30 days were studied.

\section{Cost data collection and cost-savings projection}

Costs related to the in-hospital treatment and readmission up to 30 days after discharge were obtained from the Premier database and compared in patients with and without complications. Costs are those associated with the actual procedures, as determined by the hospital using its accounting systems, and include both fixed and variable components.

The recently published JAMA meta-analysis by Pearse et al. (Pearse et al. 2014) was used to estimate the potential reduction in postoperative morbidity with GDFT. This meta-analysis reported an average $23 \%$ reduction in odds of a postoperative complication (odds ratio 0.77 , $95 \%$ CI 0.71 to $0.83, p<0.05$ ) associated with the use of GDFT. Potential cost-savings were determined by using the projected number of patients developing one or more complications and the estimated related costs. This analysis was performed for the entire cohort, as well as for each surgical procedure. The analysis assumes a complete, new implementation of GDFT.

\section{Statistical analysis}

Hospital LOS, readmission rates, and costs were compared between patients with and without complications. Readmission rates (\%) were compared using chi-squared tests and hospital LOS (median \pm interquartiles), and costs (mean $\pm \mathrm{SD}$ ) were compared using Wilcoxon rank- 
sum and $t$ tests, respectively. All statistical comparisons were considered statistically significant assuming a twotailed alpha level of 0.05 .

Total costs were further analyzed using multivariable generalized linear models. The models utilized a gamma distribution and log link to account for the skewness in the outcome data. The model estimated the least-squares mean total costs while controlling for potential confounding variables including patient age, gender, co-morbidities (as measured by the CCI), and elective/non-elective admission. An additional model was performed as a sensitivity analysis and added the type of surgery to the other potential confounders.

\section{Results}

A total of 204,680 patients from 541 medical centers met the search criteria. Among these centers, $86.6 \%$ were urban, $58.3 \%$ were non-teaching hospitals, and $65.7 \%$ had 300 or more beds. Patients' characteristics are summarized in Table 1 . Numbers of patients per surgery group are reported in Table 2. A total of 76,807 patients developed one or more postsurgical complications (average morbidity rate $37.5 \%$ ). Complication rates $\geq 1 \%$ are shown in Fig. 1 . Morbidity rates for each surgery group are presented in Table 3 .

\section{Impact of postsurgical complications on hospital length of stay and readmission rate}

In patients with one or more complications and in patients without any complications, 30-day readmission rates were 17.2 and $11.9 \%(p<0.001)$, respectively. Median hospital length of stay was $7[4,10]$ (25th-75th percentiles) and 4 $[3,5]$ days $(p<0.001)$, respectively. The impact of postoperative complications on hospital length of stay and 30-day readmission rates for each surgery group is presented in Table 2.

\section{Economic impact of postsurgical complications}

Average unadjusted costs (index hospitalization + 30day readmission costs when applicable) were US $\$ 27,607 \pm 32,788$ per patient with one or more complications $(n=73,108)$ and US $\$ 15,783 \pm 12,282$ $(p<0.001)$ per patient with no complications $(n=127,398)$.

Table 1 Characteristics of the study population

\begin{tabular}{|c|c|c|c|}
\hline & $\begin{array}{l}\text { All } \\
n=204,680\end{array}$ & $\begin{array}{l}\text { With complications } \\
n=76,807\end{array}$ & $\begin{array}{l}\text { Without complications } \\
n=127,873\end{array}$ \\
\hline Age (years) & $64.8 \pm 17.2$ & $68.8 \pm 16.0$ & $62.4 \pm 17.4$ \\
\hline Gender (\% female) & 58.8 & 58.4 & 59.0 \\
\hline Elective surgery (\%) & 54.8 & 45.2 & 60.5 \\
\hline ICU admission (\%) & 22.4 & 36.2 & 14.1 \\
\hline Mortality (\%) & 1.9 & 4.6 & 0.2 \\
\hline Myocardial infarction (\%) & 6.2 & 8.8 & 4.6 \\
\hline Congestive heart failure (\%) & 7.5 & 12.3 & 4.6 \\
\hline Peripheral vascular disease (\%) & 7.3 & 9.0 & 6.2 \\
\hline Cerebrovascular disease (\%) & 2.0 & 3.2 & 1.4 \\
\hline Hemiplegia or paraplegia (\%) & 0.4 & 0.7 & 0.2 \\
\hline Dementia (\%) & 0.8 & 1.1 & 0.5 \\
\hline Chronic pulmonary disease (\%) & 19.3 & 23.8 & 16.6 \\
\hline Rheumatologic disease (\%) & 2.6 & 3.0 & 2.3 \\
\hline Peptic ulcer disease (\%) & 1.3 & 1.9 & 0.9 \\
\hline Mild liver disease (\%) & 1.0 & 1.3 & 0.8 \\
\hline Moderate or severe liver disease (\%) & 0.4 & 0.6 & 0.2 \\
\hline Diabetes (\%) & 19.9 & 21.1 & 19.2 \\
\hline Diabetes with complications (\%) & 2.2 & 2.8 & 1.9 \\
\hline Renal disease (\%) & 9.3 & 14.1 & 6.3 \\
\hline Any malignancy (\%) & 22.1 & 24.1 & 20.8 \\
\hline Metastatic solid tumor (\%) & 6.6 & 7.7 & 6.0 \\
\hline AIDS (\%) & 0.1 & 0.1 & 0.1 \\
\hline Charlson Co-morbidity Index & $1.8 \pm 2.3$ & $2.2 \pm 2.5$ & $1.5 \pm 2.2$ \\
\hline
\end{tabular}

All comparisons "with complications vs. without complications" were statistically significant with $p<0.0001$, with the exception of gender ( $p=0.0386)$ and AIDS $(p=0.2912)$ 
Table 2 Hospital length of stay (HLOS), 30-day readmission rate, and costs in patients with one or more complications (with) and in patients without any complications (without)

\begin{tabular}{|c|c|c|c|c|c|c|}
\hline \multirow{2}{*}{$\begin{array}{l}\text { Surgery } \\
n\end{array}$} & \multicolumn{2}{|c|}{ HLOS, days, median [IQR] } & \multicolumn{2}{|c|}{ Readmission rate, $\%$} & \multicolumn{2}{|c|}{ Cost, dollar ${ }^{\mathrm{a}}$, mean \pm SD } \\
\hline & With & Without & With & Without & With & Without \\
\hline All & $7[4-10]$ & $4[3-5]$ & 17.2 & 11.9 & $27,607 \pm 32,788$ & $15,783 \pm 12,282$ \\
\hline \multicolumn{7}{|l|}{204,680} \\
\hline AAA open repair & $8[6-14]$ & $6[4-7]$ & 16.5 & 8.7 & $48,002 \pm 48,841$ & $24,619 \pm 14,543$ \\
\hline \multicolumn{7}{|l|}{2328} \\
\hline Vascular bypass & 6 [4-9] & $3[2-5]$ & 21.3 & 14.1 & $31,979 \pm 30,386$ & $16,849 \pm 12,543$ \\
\hline \multicolumn{7}{|l|}{16,336} \\
\hline Esophagectomy & 13 [9-20] & $9[8-11]$ & 18.5 & 15.4 & $67,924 \pm 65,377$ & $37,382 \pm 17,973$ \\
\hline \multicolumn{7}{|l|}{690} \\
\hline Gastrectomy & $4[2-10]$ & $2[1,2]$ & 12.7 & 5.2 & $27,794 \pm 33,530$ & $12,641 \pm 9,452$ \\
\hline \multicolumn{7}{|l|}{25,118} \\
\hline Colectomy & $8[5-11]$ & $4[3-6]$ & 15.2 & 9.0 & $27,851 \pm 29,286$ & $14,755 \pm 10,524$ \\
\hline \multicolumn{7}{|l|}{75,121} \\
\hline Resection of rectum & $7[5-11]$ & $5[3-6]$ & 15.2 & 10.4 & $26,916 \pm 24,466$ & $15,979 \pm 18,855$ \\
\hline \multicolumn{7}{|l|}{10,753} \\
\hline Hepatectomy & $7[5-11]$ & $5[3-6]$ & 17.9 & 9.4 & $37,315 \pm 38,100$ & $20,272 \pm 13,566$ \\
\hline \multicolumn{7}{|l|}{2362} \\
\hline Pancreatectomy & $11[8-18]$ & 7 [5-9] & 26.1 & 18.6 & $50,559 \pm 46,784$ & $27,488 \pm 19,653$ \\
\hline \multicolumn{7}{|l|}{3569} \\
\hline Cystectomy & $10[7-14]$ & 7 [6-8] & 29.2 & 21.9 & $41,128 \pm 38,293$ & $25,978 \pm 15,061$ \\
\hline \multicolumn{7}{|l|}{2552} \\
\hline F\&H fracture repair & $5[4-7]$ & $4[3-5]$ & 18.9 & 17.4 & $22,218 \pm 32,644$ & $16,805 \pm 12,167$ \\
\hline 65,851 & & & & & & \\
\hline
\end{tabular}

All comparisons "with vs. without" were statistically significant with $p<0.0001$

$A A A$ abdominal aortic aneurysm, F\&H femur and hip

${ }^{a}$ For patients with valid cost data, unadjusted

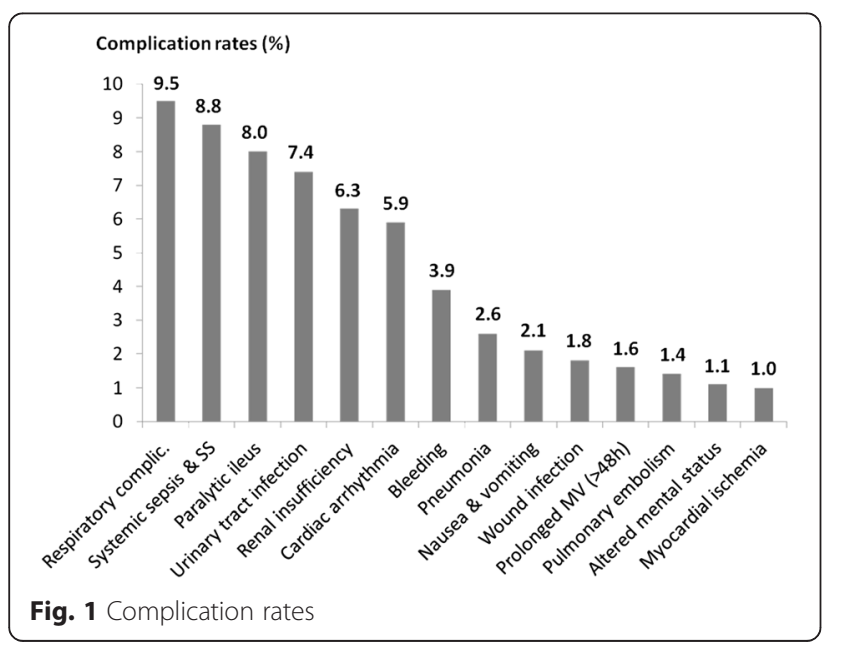

In other words, patients with one or more complications were on average US $\$ 11,824$ more costly than patients with no complications. Thus, from January 2011 to June 2013, the 541 hospitals whose data were used in these analyses spent an estimated total of more than US $\$ 908$ million (US $\$ 11,824 \times 76,807$ patients) to treat postsurgical complications in the study population (US\$363 million per year). The economic impact of postoperative complications for each surgery group is presented in Table 2.

Results from the multivariable model were directionally consistent with the descriptive analysis. The average estimated costs after controlling for confounders were significantly different, US $\$ 25,390$ vs. US $\$ 14,841 \quad(p<$ 0.001 , cost difference US $\$ 10,549)$ per patient with one or more complications and per patient with no complications, respectively. Furthermore, when the model also controlled for the type of surgery, the estimated costs remained significantly different (US $\$ 32,182$ vs. $\$ 19,803$; $p<0.001$, cost difference US $\$ 12,379)$. 
Table 3 Morbidity rate, cost difference between patients with and without complications, and expected savings per patient receiving goal-directed fluid therapy (GDFT)

\begin{tabular}{lcll}
\hline Surgery & $\begin{array}{l}\text { Morbidity } \\
\text { rate, \% }\end{array}$ & $\begin{array}{l}\text { Cost difference between } \\
\text { patients with and without } \\
\text { complications, dollar }\end{array}$ & $\begin{array}{l}\text { Potential savings } \\
\text { per patient with } \\
\text { GDFT, dollar }\end{array}$ \\
\hline All & 37.5 & 11,824 & $754-1286$ \\
$\begin{array}{l}\text { AAA open } \\
\text { repair }\end{array}$ & 64.9 & 23,383 & $2580-4401$ \\
$\begin{array}{l}\text { Vascular bypass } \\
\text { Esophagectomy }\end{array}$ & 26.3 & 15,130 & $676-1154$ \\
$\begin{array}{l}\text { Gastrectomy } \\
\text { Colectomy }\end{array}$ & 20.2 & 15,153 & $3515-5996$ \\
$\begin{array}{l}\text { Resection of } \\
\text { rectum }\end{array}$ & 33.3 & 13,096 & $520-888$ \\
Hepatectomy & 34.3 & 10,937 & $964-1644$ \\
$\begin{array}{l}\text { Pancreatectomy } \\
\text { Cystectomy }\end{array}$ & 47.5 & 23,071 & $625-1066$ \\
$\begin{array}{l}\text { F\&H fracture } \\
\text { repair }\end{array}$ & 58.9 & 15,150 & $994-1695$ \\
\hline AAA abdomina & 38.5 & 5413 & $1863-3178$ \\
& & & $354-604$ \\
\hline
\end{tabular}

$A A A$ abdominal aortic aneurysm, F\&H femur and hip

${ }^{a}$ For patients with valid cost data, unadjusted

\section{Projected cost-savings with implementation of GDFT}

The projected number of patients developing one or more complications, assuming an odds ratio ranging between 0.71 and 0.83 , was $54,533-63,750$ (morbidity rate 26.6$31.1 \%)$. Thus, after implementation of GDFT, projected gross savings were US\$153-263 million for the study period, US\$61-105 million per year, or US\$754-1286 per patient (Table 3). Projected cost-savings per year for each surgery group are presented in Fig. 2.

\section{Discussion}

In our large patient population who underwent major non-cardiac surgery, postoperative complications were observed in more than one third of the cases and increased costs on average by US\$11,824 per patient (+75\%). These findings are consistent with those reported by previous and smaller studies. In 1008 patients who underwent general and vascular surgery, Dimick et al. (Dimick et al. 2006) reported a US\$10,178 cost difference between patients with and without complications. In a similar surgical population, Boltz et al. (Boltz et al. 2012) showed in 2250 patients that the excess costs were US\$6358, US\$12,802, and US\$42,790 for patients developing 1, 2, 3 or more complications, respectively. In the present study, the occurrence of postoperative complications was also associated with prolonged length of stay ( +3 days) and increased hospital readmission rates at 30 days $(+5.3 \%$ absolute increase, $+44 \%$ relative increase). These findings are consistent with previous reports (Eappen et al. 2013; Lawson et al. 2013)

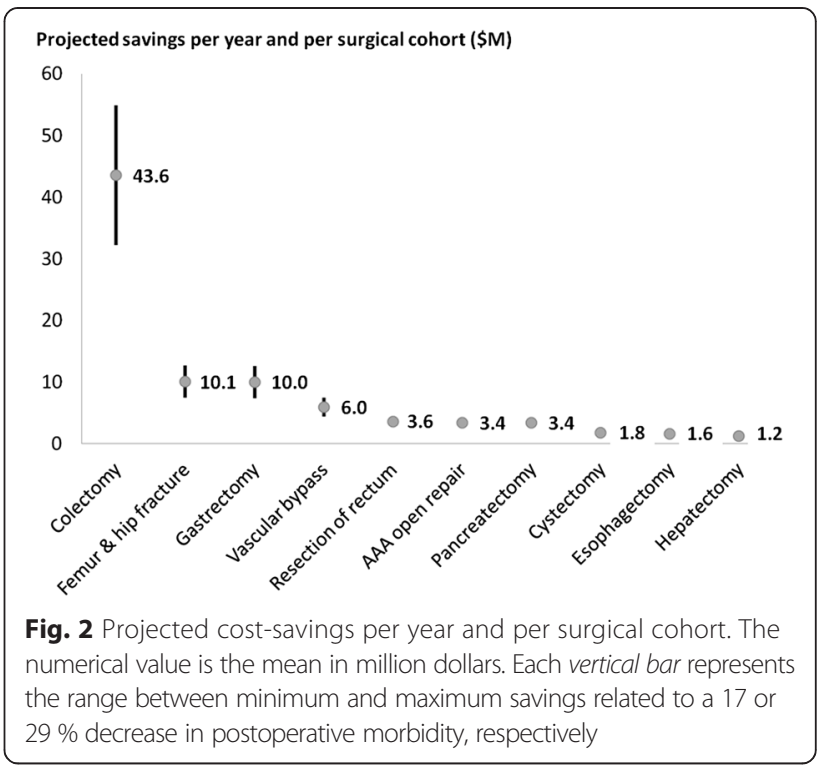

emphasizing the dramatic impact of complications on length of stay and readmission rates. This highlights a relevant savings capacity for major surgical procedures.

According to a recent meta-analysis of 38 randomized controlled trials, GDFT has the potential to decrease postoperative morbidity by $17-29 \%$ (Pearse et al. 2014). In our study population, such a decrease in postoperative morbidity would translate into cost-savings ranging between US\$754 and US\$1286 per patient. Interestingly, potential savings were highly variable from one surgical procedure to the other (Table 3). Two factors affect savings per patient: the actual morbidity rate (the higher the morbidity rate, the higher the savings when all patients receive GDFT) and the cost of complications (the higher the cost, the higher the savings). The actual morbidity rates ranged from $20.2 \%$ for gastrectomies to $67.7 \%$ for esophagectomies (Table 3), and cost of complications ranged from US $\$ 5413$ for femur and hip-fracture repair to US $\$ 30,542$ for esophagectomies (Table 3). This large range in morbidity rates and costs of complications explain why the range of potential savings with GDFT was also wide, from US\$354-604/patient for femur and hip-fracture repair to US\$3515-5996/patient for esophagectomies (Table 3). A third factor affects savings at the hospital level: the volume of surgeries. When taking into account the volume of procedures, the total potential savings per year were the most significant (US\$32-55 million), for colectomies, by far (Fig. 2). This finding supports the notion that GDFT should be implemented as a priority in this surgical population.

Three recent studies tried to estimate potential savings related to the use of GDFT. The first study (Bartha et al. 2012) from Sweden is a decision analytic model where 
assumptions were made regarding morbidity rates before and after GDFT implementation, as well as on hospital costs. This study focused on elderly hip-fracture patients, and the model estimated a $1882 €$ (around US\$2000) cost reduction per patient with GDFT. The second study from the UK was based on a small population of 122 patients who underwent major surgery (Ebm et al. 2014). Morbidity rates before and after GDFT implementation were real, but assumptions were made regarding hospital costs. This study suggested a cost reduction of $£ 2631$ (around US\$4000) per patient with GDFT. Differences between US and European healthcare systems and costs, as well as the fact that costs were not real but estimated in the Swedish and the UK study, may explain why they both reported potential savings higher than our projections. In the third study, Manecke et al. (Manecke et al. 2014) used real morbidity rates and real costs extracted from the UHC database, which is a large administrative database containing clinical and economic data from over 120 US academic hospitals. As in our study, the only assumption made was related to the reduction in postoperative morbidity with GDFT. Manecke et al. (Manecke et al. 2014) reported potential cost-savings ranging from US\$569 to US $\$ 970$ per patient, i.e., slightly lower than ours. The UHC database contains only 11 possible postoperative complications and is known to underestimate postoperative morbidity rates (Steinberg et al. 2008). For instance, they did not take into account postoperative paralytic ileus, which is not a major complication but a frequent one (Fig. 1), known to have a significant impact on hospital length of stay and costs (Iyer et al. 2009). Finally, the economic evaluation of Manecke et al. (Manecke et al. 2014) did not include 30-day readmission costs, and was limited to academic hospitals. Our analysis was based on a larger number of patients and considered 26 different postoperative complications (including paralytic ileus). We took into account 30-day readmission costs, and $58.2 \%$ of our study population came from non academic centers. For these reasons, we believe that our study provides a more accurate estimation of potential savings associated with the implementation of GDFT at a national level.

To assess a return of investment, our projected savings must be balanced with costs related to GDFT implementation. Assuming average cardiac output-monitoringrelated costs of US $\$ 300$ per patient (US $\$ 250$ for disposable sensor + US $\$ 48$ for the amortization of a US $\$ 15,000$ monitor used two times a week over 3 years), our findings suggest that for each dollar spent to implement GDFT, hospitals should save in return between US $\$ 2.5$ and US\$4. GDFT implementation costs may vary from one hospital to the other, but each hospital could easily forecast the return on investment using its own costs and our model.
Another major burden of complications is the opportunity cost of lost beds for increased length of stay and readmissions in patients with complications. In busy hospitals, these are beds not taken by new patients with new DRGs and the accompanying payments. With an increased length of stay of 3 days for patients with complications (Table 2), the 76,807 patients with complications represent $230,421(3 \times 76,807)$ days lost. With the assumption that GDFT would decrease the number of patients with one or more complications to $54,533-63,750$ (a 17 to $29 \%$ decrease), it would now represent only 163,599-191,250 days lost. In other words, GDFT has the potential to save between 39,171 and 66,822 days. With the average hospital length of stay across all studied surgical cohorts being 5 days, the implementation of GDFT could result in 783413,364 (39,171 and 66,822 divided by 5 ) new patients admitted in our 541 hospitals over the 2.5-year study period, or 3134-5346 new patients per year. Since payments to hospitals vary so widely, each hospital can use this approach to calculate the increased payment and profit to the bottom line. This is the lost opportunity cost of having patients with complications take up hospital beds needed for other patients and represents the potential additional profit to the hospital. This may easily outweigh the savings from decreased complications.

Our study has certain limitations that should be considered. The analysis was limited to specific major surgeries in which outcome has already conclusively been shown to be improved by the use of GDFT. There are other surgeries, such as major spine and gynecologic surgeries, in which this approach would likely be associated with fewer complications (Mythen et al. 2012; Gan et al. 2002). Our study assumes complete implementation of GDFT, which may be an unrealistic goal. Also, we considered the same postsurgical morbidity reduction with GDFT for all surgical procedures, which may not always be the case. However, previous meta-analysis (Pearse et al. 2014; Hamilton et al. 2011) did not find any interaction between the type of surgery and the effect of GDFT. The article by Pearse et al. (Pearse et al. 2014) was chosen to estimate the effect of GDFT on postoperative morbidity because it is the most recent meta-analysis on the topic. It is important to note that it included studies published many years ago. Because both anesthesia and surgical practices changed over time, the assumption that GDFT would reduce postoperative morbidity by $17-29 \%$ may be questioned in 2015 . A metaanalysis by Hamilton et al. (Hamilton et al. 2011) studied the clinical effects of GDFT over time. If GDFT had no effect on mortality in studies published after 2000, the reduction in postoperative morbidity was still highly significant, ranging between 50 and $71 \%$ (average odds ratio $0.38, \mathrm{CI}$ 0.29 to 0.50 ). Interestingly, if we had used these odds ratios for our calculations, the projected savings with GDFT would have been much higher than those we have 
reported. Having said that, we must acknowledge that enhanced recovery programs have gained acceptance only recently, as well as changes in the type of fluid administered during the perioperative period (starches and unbalanced crystalloid solutions are used less often). Therefore, the clinical effects of GDFT in this new perioperative medicine era remain to be evaluated by large studies. Finally, we did not have access to reimbursement data, so we were unable to study the effects of morbidity reduction on hospital profit or profit margin, another very important economic driver for the hospital adoption of any new therapeutic strategy (Dimick et al. 2006; Flynn et al. 2014).

\section{Conclusions}

In patients who underwent major non-cardiac surgery, our study demonstrates that postsurgical complications are frequent and have a significant impact on hospital length of stay, readmission rates, and costs. It also suggests significant savings with GDFT; for each dollar spent to implement GDFT, our projections suggest that hospitals should save in return between US\$2.5 and US\$4. Projected cost-savings were the highest for the colectomy cohort, suggesting that priority should be given to the implementation of GDFT in this patient population.

\section{Additional files}

Additional file 1: The 10 major surgical procedures, with the corresponding ICD-9 procedure codes. DOC $72.5 \mathrm{~kb}$

Additional file 2: The 26 postsurgical complications, with the corresponding ICD-9 diagnostic codes. DOC $58.0 \mathrm{~kb}$

\section{Abbreviations}

GDFT: Goal-directed fluid therapy; CCl: Charlson co-morbidity Index.

\section{Competing interests}

FM is an employee of Edwards Lifesciences, and SLF received consulting fees from Edwards Lifesciences. However, this manuscript does not support the use of any specific medical device for GDFT. MRK, WKM and FRE were employees of Premier, Inc. at the time of the analyses.

\section{Authors' contributions}

FM designed the study, participated in the interpretation of data, drafted the manuscript, and revised it critically for important intellectual content. WKM, MRK, and FRE participated in data analysis and revised the manuscript critically for important intellectual content. SLF has been involved in the interpretation of data and revised the manuscript critically for important intellectual content. All authors read and approved the final manuscript.

\section{Acknowledgements}

The study was sponsored by Edwards Lifesciences, and the analysis was performed by Premier Inc.

\section{Author details}

'Department of Critical Care, Edwards Lifesciences, 1 Edwards Way, Irvine, CA, USA. ${ }^{2}$ Premier Inc., Charlotte, NC, USA. ${ }^{3}$ Current address: Quintiles, Durham, NC, USA. ${ }^{4}$ Current address: Quintiles, Cambridge, MA, USA. ${ }^{5}$ Current address: Indegene Total Therapeutic Management, Kennesaw, GA, USA. Virginia Tech Carilion School of Medicine, Roanoke, VA, USA.
Received: 24 June 2015 Accepted: 8 October 2015

Published online: 19 October 2015

\section{References}

Artinyan A, Orcutt ST, Anaya DA. Infectious postoperative complications decrease long-term survival in patients undergoing curative surgery for colorectal cancer: a study of 12,075 patients. Ann Surg. 2015;261:497-505.

Bartha E, Davidson T, Hommel A. Cost effectiveness analysis of goal-directed hemodynamic treatment of elderly hip fracture patients. Anesthesiology. 2012;117:519-30.

Bellamy MC. Wet, dry, or something else? Br J Anaesth. 2006;97:755-7.

Benes J, Chytra I, Altmann P. Intraoperative fluid optimization using stroke volume variation in high risk surgical patients: results of prospective randomized study. Crit Care. 2010;14:R118.

Birkmeyer JD, Gust C, Dimick JB. Hospital quality and the cost of inpatient surgery in the United States. Ann Surg. 2012;255:1-5.

Bisgaard J, Gilsaa T, Ronholm E. Haemodynamic optimisation in lower limb arterial surgery: room for improvement? Acta Anaesthesiol Scand. 2013:57:189-98

Boltz MM, Hollenbeak CS, Ortenzi G. Synergistic implications of multiple postoperative outcomes. Am J Med Qual. 2012;27:383-90.

Boyd O, Grounds RM, Bennett ED. A randomized clinical trial of the effect of deliberate perioperative increase of oxygen delivery on mortality in high-risk surgical patients. JAMA. 1993;270:2699-707.

Brown SR, Mathew R, Keding A. The impact of postoperative complications on long-term quality of life after curative colorectal cancer surgery. Ann Surg. 2014;259:916-23.

Cannesson M, Pestel G, Ricks C. Hemodynamic monitoring and management in patients undergoing high risk surgery: a survey among North American and European anesthesiologists. Crit Care. 2011;15:R197.

Charlson M, Szatrowski TP, Peterson J. Validation of a combined comorbidity index. J Clin Epidemiol. 1994;47:1245-51.

Dimick JB, Chen SL, Taheri PA. Hospital costs associated with surgical complications: a report from the private-sector national surgical improvement program. J Am Coll Surg. 2004;199:531-7.

Dimick JB, Weeks WB, Karia RJ. Who pays for poor surgical quality? Building a business case for quality improvement. J Am Coll Surg. 2006;202:933-7.

Eappen S, Lane BH, Rosenberg B. Relationship between occurrence of surgical complications and hospital finances. JAMA. 2013;309:1599-606.

Ebm C, Cecconi M, Sutton L. A cost-effectiveness analysis of postoperative goal directed therapy for high-risk surgical patients. Crit Care Med. 2014:42:1194-203.

Flynn DN, Speck RM, Mahmoud NN. The impact of complications following open colectomy on hospital finances: a retrospective cohort study. Perioper Med. 2014;3:1

Gan TJ, Soppitt A, Maroof M. Goal-directed intraoperative fluid administration reduces length of hospital stay after major surgery. Anesthesiology. 2002:97:820-6.

Ghaferi AA, Birkmeyer JD, Dimick JB. Variation in hospital mortality associated with inpatient surgery. N Engl J Med. 2009:361:1368-75.

Gustafsson UO, Scott MJ, Schwenk W. Guidelines for perioperative care in elective colonic surgery: enhanced recovery after surgery (ERAS) society. World J Surg. 2013;37:259-84.

Hamilton M, Cecconi M, Rhodes A. A systematic review and meta-analysis on the use of preemptive hemodynamic intervention to improve outcomes in moderate and high-risk surgery. Anesth Analg. 2011;112:1392-402.

lyer S, Saunders WB, Stemkowski S. Economic burden of postoperative ileus associated with colectomy in the United States. J Manag Care Pharm. 2009;15:485-94.

Khuri SF, Henderson WG, DePalma RG. Determinants of long-term survival after major surgery and the adverse effect of postoperative complications. Ann Surg. 2005;242:326-43.

Kuper M, Gold SJ, Callow C. Intraoperative fluid management guided by oesophageal Doppler monitoring. BMJ. 2011;342:d3016.

Lawson EH, Hall BL, Louie R. Association between occurrence of a postoperative complication and readmission. Ann Surg. 2013;258:10-8.

Lilot M, Erhenfeld JM, Lee C. Variability in practice and factors predictive of total crystalloid administration during abdominal surgery: retrospective two-centre analysis. Br J Anaesth. 2015;114:767-76.

Lobo SMA, Salgado PF, Castillo VGT. Effects of maximizing oxygen delivery on morbidity and mortality in high-risk surgical patients. Crit Care Med. 2000;28:3396-404 
Manecke G, Asemota A, Michard F. Tackling the economic burden of postsurgical complications: would goal directed fluid therapy help? Crit Care. 2014;18:566. Merkow RP, Ju MH, Chung JW. Underlying reasons associated with hospital readmission following surgery in the United States. JAMA. 2015;315:483-95.

Miller TE, Roche AM, Gan TJ. Poor adoption of hemodynamic optimization during major surgery: are we practicing substandard care? Anesth Analg. 2011;112:1274-6.

Mythen MG, Swart M, Acheson N. Perioperative fluid management: consensus statement from the enhanced recovery partnership. Perioper Med. 2012;1:2.

Navarro LHC, Bloomstone JA, Auler Jr JOC. Perioperative fluid theory: a statement from the international Fluid Optimization Group. Perioper Med. 2015;4:3.

Noblett SE, Snowden CP, Shenton BK. Randomized clinical trial assessing the effect of Doppler-optimized fluid management on outcome after elective colorectal resection. Br J Surg. 2006;93:1069-76.

Pearse R, Dawson D, Fawcett J. Early goal-directed therapy after major surgery reduces complications and duration of hospital stay. A randomised, controlled trial [ISRCTN38797445]. Crit Care. 2005;9:R687-93.

Pearse RM, Harrison DA, McDonald N. Effect of a perioperative, cardiac outputguided, hemodynamic therapy algorithm on outcomes following major gastrointestinal surgery: a randomized clinical trial and updated systematic review. JAMA. 2014;311:2181-90.

Pillai P, McEleavy I, Gaughan M. A double-blind randomized controlled clinical trial to assess the effect of Doppler optimized intraoperative fluid management on outcome following radical cystectomy. J Urol. 2011;186:2201-6.

Ramsingh DS, Sanghvi C, Gamboa J. Outcome impact of goal directed fluid therapy during high risk abdominal surgery in low to moderate risk patients: a randomized controlled trial. J Clin Monit Comput. 2013;27:249-57.

Sinclair S, James S, Singer M. Intraoperative intravascular volume optimisation and length of hospital stay after repair of proximal femoral fracture: randomised controlled trial. BMJ. 1997;315:909-12.

Steinberg SM, Popa MR, Michalek JA. Comparison of risk adjustment methodologies in surgical quality improvement. Surgery. 2008;144:662-9.

Ueno S, Tanabe G, Yamada H. Response of patients with cirrhosis who have undergone partial hepatectomy to treatment aimed at achieving supranormal oxygen delivery and consumption. Surgery. 1998;123:278-86.

Vallet B, Blanloeil Y, Cholley B. Guidelines for perioperative haemodynamic optimization. Ann Fr Anesth Reanim. 2013;32:454-62.

Venn R, Steele A, Richardson P, Poloniecki J. Randomized controlled trial to investigate influence of the fluid challenge on duration of hospital stay and perioperative morbidity in patients with hip fractures. Br J Anaesth. 2002;88:65-71.

Wakeling HG, MCFall MR, Jenkins CS. Intraoperative oesophageal Doppler guided fluid management shortens postoperative hospital stay after major bowel surgery. Br J Anaesth. 2005;95:634-42.

Wick EC, Shore AD, Hirose K. Readmission rates and cost following colorectal surgery. Dis Colon Rectum. 2011;54:1475-9.

Wilson J, Woods I, Fawcett J. Reducing the risk of major elective surgery: randomised controlled trial of preoperative optimisation of oxygen delivery. BMJ. 1999:318:1099-103.

\section{Submit your next manuscript to BioMed Central and take full advantage of:}

- Convenient online submission

- Thorough peer review

- No space constraints or color figure charges

- Immediate publication on acceptance

- Inclusion in PubMed, CAS, Scopus and Google Scholar

- Research which is freely available for redistribution

Submit your manuscript at www.biomedcentral.com/submit 